\title{
Ambient air pollution is associated with pediatric pneumonia: a time-stratified case-crossover study in an urban area
}

\author{
Chi-Yung Cheng ${ }^{1,2 \dagger}$, Shih-Yu Cheng ${ }^{2,3 \dagger}$, Chien-Chih Chen ${ }^{1,2}$, Hsiu-Yung Pan ${ }^{1,2}$, Kuan-Han Wu ${ }^{1,2}$ and \\ Fu-Jen Cheng ${ }^{1,2^{*}}$
}

\begin{abstract}
Background: Pneumonia, the leading reason underlying childhood deaths, may be triggered or exacerbated by air pollution. To date, only a few studies have examined the association of air pollution with emergency department (ED) visits for pediatric pneumonia, with inconsistent results. Therefore, we aimed to elucidate the impact of shortterm exposure to particulate matter (PM) and other air pollutants on the incidence of ED visits for pediatric pneumonia.

Methods: $\mathrm{PM}_{2.5}, \mathrm{PM}_{10}$, and other air pollutant levels were measured at 11 air quality-monitoring stations in Kaohsiung City, Taiwan, between 2008 and 2014. Further, we extracted the medical records of non-trauma patients aged $\leq 17$ years and who had visited an ED with the principal diagnosis of pneumonia. A time-stratified case-crossover study design was employed to determine the hazard effect of air pollution in a total of 4024 patients.

Results: The single-pollutant model suggested that per interquartile range increment in $\mathrm{PM}_{2.5}, \mathrm{PM}_{10}$, nitrogen dioxide $\left(\mathrm{NO}_{2}\right)$, and sulfur dioxide $\left(\mathrm{SO}_{2}\right)$ on 3 days before the event increased the odds of pediatric pneumonia by $14.0 \%$ [95\% confidence interval (Cl), 5.1-23.8\%], 10.9\% (95\% Cl, 2.4-20.0\%), 14.1\% (95\% Cl, 5.0-24.1\%), and 4.5\% (95\% Cl, 0.8-8.4\%), respectively. In two-pollutant models, $\mathrm{PM}_{2.5}$ and $\mathrm{NO}_{2}$ were significant after adjusting for $\mathrm{PM}_{10}$ and $\mathrm{SO}_{2}$. Subgroup analyses showed that older children (aged $\geq 4$ years) were more susceptible to $\mathrm{PM}_{2.5}$ (interaction $p=0.024$ ) and children were more susceptible to $\mathrm{NO}_{2}$ during warm days $\left(\geq 26.5^{\circ} \mathrm{C}\right.$, interaction $\left.p=0.011\right)$.

Conclusions: Short-term exposure to $\mathrm{PM}_{2.5}$ and $\mathrm{NO}_{2}$ possibly plays an important role in pediatric pneumonia in Kaohsiung, Taiwan. Older children are more susceptible to $\mathrm{PM}_{2.5}$, and all children are more susceptible to $\mathrm{NO}_{2}$ during warm days.
\end{abstract}

Keywords: Particulate matter, Air pollution, Pediatric, Pneumonia, Season

\section{Introduction}

Many epidemiological studies have reported that shortterm variations in ambient air pollution are related to poor health outcomes, such as respiratory diseases, cardiovascular diseases, and mortality [1-4]. Particulate matter $(\mathrm{PM})$, nitrogen dioxide $\left(\mathrm{NO}_{2}\right)$, and ozone $\left(\mathrm{O}_{3}\right)$ are reportedly related to hospital admissions for pneumonia [5]. Epidemiological studies suggest that fine particles (which

\footnotetext{
* Correspondence: a0953283092@yahoo.com.tw

Co-first authors: Chi-Yung Cheng and Shih-Yu Cheng

'Department of Emergency Medicine, Kaohsiung Chang Gung Memorial Hospital,

No. 123, Dapi Rd., Niaosong Township, Kaohsiung, County 833, Taiwan

${ }^{2}$ Chang Gung University College of Medicine, No.259, Wenhua 1st Road,

Guishan District, Taoyuan City 333, Taiwan

Full list of author information is available at the end of the article
}

are usually defined as PM having an aerodynamic diameter of $<2.5 \mu \mathrm{m} ; \mathrm{PM}_{2.5}$ ) are more toxic than larger particles [6].

Pneumonia, an inflammatory lung condition, is the leading cause of death in children, accounting for approximately 1.3 million deaths among children aged $<5$ years in 2010-2011 [7]. Air pollutants, such as $\mathrm{PM}_{10}$ (PM having an aerodynamic diameter of $<10 \mu \mathrm{m}$ ), $\mathrm{PM}_{2.5}, \mathrm{NO}_{2}$, and $\mathrm{O}_{3}$ are related to lung and systemic inflammation [8-10]. The health effects of air pollutants seemed to have regional and seasonal variations. The regional heterogeneity between the estimated effect of PM on hospitalization and mortality has been reported in several previous multi-city studies $[1,11]$. These

(c) The Author(s). 2019 Open Access This article is distributed under the terms of the Creative Commons Attribution 4.0 International License (http://creativecommons.org/licenses/by/4.0/), which permits unrestricted use, distribution, and reproduction in any medium, provided you give appropriate credit to the original author(s) and the source, provide a link to the Creative Commons license, and indicate if changes were made. The Creative Commons Public Domain Dedication waiver (http://creativecommons.org/publicdomain/zero/1.0/) applies to the data made available in this article, unless otherwise stated. 
seasonal and regional variations might be explained by certain community characteristics, for instance, air conditioning [12], population density [13], the proportion of elderly residents [1], and effect modification by ambient temperature [2]. Previous studies also demonstrated that the effect of $\mathrm{PM}_{2.5}$ on emergency hospitalizations for pneumonia [14] was greater for children and its effect on out-of-hospital cardiac arrest (OHCA) was greater in elderly patients [15]. For children, air pollution was found to be associated with emergency department (ED) admission for respiratory diseases and asthma [16, 17]. However, only a limited number of studies have focused on air pollution and ED visits for pediatric pneumonia, and the results are inconsistent [18, 19]. Furthermore, only limited information is available regarding the pediatric populations which are particularly susceptible to these exposures.

Over a 7-year period, in South Taiwan, we collected data of pediatric patients who presented at the ED from a tertiary academic medical center due to pneumonia. Using a case-crossover design, the data were analyzed with respect to weather and air pollution parameters. The study aimed: (1) to evaluate correlation between increase in short-term exposure to air pollutants and events of pediatric pneumonia and (2) to evaluate the potential triggering effects of $\mathrm{PM}_{2.5}$, especially in individuals with pre-existing disease.

\section{Materials and methods Kaohsiung City}

Kaohsiung is located in the southwestern part of Taiwan and has a tropical monsoon climate. It is the leading industrial city with the largest commercial harbor in Taiwan. The industry clusters include basic metals, nonmetallic mineral products, transportation equipment manufacturing, food and agricultural products, chemical products, machinery and repairs, and power equipment and repairs.

\section{Study population}

This was a retrospective observational study conducted in an urban tertiary medical center, which has 72,000 ED visits on an average every year. The study period was from January 1, 2008 to December 31, 2014. We retrospectively reviewed the electronic medical records, and from the ED's administrative database, extracted data of non-trauma patients who were $\leq 17$ years old and had visited an ED with a documented pneumonia diagnosis (International Classification of Diseases, ninth revision [ICD-9]: 480-486). We abstracted the following characteristics from the electronic charts: age, sex, and underlying conditions, including respiratory diseases (such as chronic respiratory failure and restrictive lung), cerebral palsy, asthma, and epilepsy.
This study was approved by the institutional review board of our hospital (no. 201801301B0) and has been performed in accordance with the ethical standards of the 1964 Declaration of Helsinki and its later amendments. For this type of study, informed consent from the subjects was not required.

\section{Pollutant and meteorological data}

In 1994, Taiwanese Environmental Protection Administration, a government agency, had constructed 11 air quality monitoring stations in Kaohsiung City. The commercial monitoring instruments of the stations were designated by the US Environmental Protection Agency as equivalent or reference instruments and manufactured by US Thermo Environmental Instruments, Inc. (Franklin, MA, USA). The automatic stations routinely monitor several "criteria" pollutant levels, including $\mathrm{NO}_{2}$ (using ultraviolet fluorescence), sulfur dioxide ( $\mathrm{SO}_{2}$, using ultraviolet fluorescence), $\mathrm{PM}_{10}$ (using beta-ray absorption), $\mathrm{PM}_{2.5}$ (using beta-ray absorption), and $\mathrm{O}_{3}$ (using ultraviolet photometry), as well as weather condition, such as temperature and humidity. Missing data accounted for less than $1 \%$ of the total data.

From all the monitoring stations, we collected air pollution data on an hourly basis, and collected addresses of pediatric pneumonia patients from medical records. In addition, we collected recordings of mean temperature and humidity on a daily basis. Finally, from the nearest monitoring station, we computed the 24 -h average pollutant levels.

\section{Statistical analysis}

To analyze pediatric pneumonia events, we employed a time-stratified case-crossover study design $[20,21]$ as an alternative to the Poisson time series regression models for estimating acute episodic events following short-term exposure attributed to air pollutants. We investigated single-day lags from the current day (lag 0) and each of 1-3 days before the pediatric pneumonia event (lag 1 , lag 2, and lag 3). We performed within-subject comparisons between case and control periods. The date of the pediatric pneumonia event was defined as case period. Time was stratified into separate months to select control periods as the days falling on the same day of the week in the same month of the same year as the case period. This self-matching control period selection strategy was considered to adjust for the effects of long-term trends, seasonality, and day of the week [22]. Using conditional logistic regression, the odds ratios (ORs) and 95\% confidence intervals (CIs) of the pediatric pneumonia cases associated with $\mathrm{PM}_{2.5}$ mass and each air pollutant were estimated. Subgroup analyses including sex, age, and underlying diseases in the most susceptible groups were also performed. Exposure levels to air pollutants were included into the pollutant models as 
continuous variables. Each model was adjusted for meteorological variables, such as average daily temperature and humidity on the same day and during lag intervals. Our analysis was conducted in two steps. First, conditional logistic regression analysis was performed using the SPSS version 25.0 software. The baseline model included a linear expression that included air pollutants and confounding factors, such as temperature and humidity. Second, we examined nonlinear effects by introducing temperature and humidity separately in the model and comparing the goodness-of-fit using the Akaike information criterion (AIC). The second step was performed using the SAS macro lgtphcurv9 (in SAS version 9.4), which implements natural cubic spline methodology to fit a potentially nonlinear response curve in conditional logistical regression models for matched casecontrol studies. With temperature, the AIC value for the linear model $(11,160.162)$ was better than that for the spline model $(11,161.772)$, and the test of curvature (nonlinear relationship) was nonsignificant $(p=0.30)$. Similarly, with humidity, the AIC value for the linear model $(11,146.628)$ was better than that for the spline model $(11,149.575)$, and the test of curvature was nonsignificant $(p=0.59)$. As a result, we used the linear model for the entire conditional logistic regression analysis.

The ORs were calculated based on interquartile range (IQR) increments in $\mathrm{PM}_{2.5}, \mathrm{PM}_{10}, \mathrm{NO}_{2}, \mathrm{SO}_{2}$, and $\mathrm{O}_{3}$ exposure. The significance criterion was set at $p<0.05$. All statistical analyses were performed with SPSS version 25.0 (IBM Corp, Armonk, NY, USA).

\section{Results}

In total, 4625 pediatric pneumonia cases were recorded in Kaohsiung over the 7-year study period. Of these, 601 patients were excluded because they were not residents of Kaohsiung City; whereas the other 4024 patients were included in the study. Table 1 lists the demographic characteristics of the 4024 patients. Among them, 2144 (53.3\%) patients were male and the mean age was $5.0 \pm$ 3.6 years. In all, $305(7.6 \%)$ cases had respiratory disease, 250 (6.2\%) had asthma, 124 (3.1\%) had cerebral palsy, and

Table 1 Characteristics of the cases $(n=4024)$

\begin{tabular}{lll}
\hline Characteristic & Number & $\%$ \\
\hline Age $($ mean \pm SD) & $5.0 \pm 3.6$ & \\
Male sex & 2144 & 53.3 \\
Respiratory disease & 305 & 7.6 \\
Asthma & 250 & 6.2 \\
Cerebral palsy & 124 & 3.1 \\
Epilepsy & 110 & 2.7 \\
Warm season & 2192 & 54.5 \\
Warm days $\left(\geq 26.5^{\circ} \mathrm{C}\right)$ & 1762 & 43.8 \\
\hline
\end{tabular}

110 (2.7\%) had epilepsy. Of the total, 2192 (54.5\%) cases occurred during the warm season (April to September), whereas 1762 (43.8\%) occurred during warm days $\left(\geq 26.5^{\circ} \mathrm{C}\right)$.

Table 2 lists the meteorological factors, daily mean concentrations of air pollutants and weather variables in Kaohsiung during the study period. The average $\mathrm{PM}_{2.5}$ and $\mathrm{PM}_{10}$ concentrations over the study period were 41.1 and $72.8 \mu \mathrm{g} / \mathrm{m}^{3}$, respectively. The average $\mathrm{NO}_{2}, \mathrm{SO}_{2}$, and $\mathrm{O}_{3}$ levels were 19.1, 6.4, and $29.1 \mathrm{ppb}$, respectively.

Table 3 shows the Pearson's correlation coefficients for the weather and air pollutant conditions. $\mathrm{PM}_{2.5}$ was highly correlated with $\mathrm{PM}_{10}(r=0.915 ; p<0.0001)$ and $\mathrm{NO}_{2}$ $(r=0.802, p<0.0001)$; and moderately correlated with $\mathrm{SO}_{2}(r=0.516, p<0.0001)$ and $\mathrm{O}_{3}(r=0.427, p<0.0001)$.

Figure 1 shows the year-round estimates of the pollutants' effects on pediatric pneumonia ED visits after adjustment for temperature and humidity. IQR increases in $\mathrm{PM}_{2.5}, \mathrm{PM}_{10}, \mathrm{NO}_{2}$, and $\mathrm{SO}_{2}$ levels on lag 3 were associated with increments of $14.0 \%$ (95\% CI, 5.1-23.8\%), 10.9\% (95\% CI, 2.4-20.0\%), 14.1\% (95\% CI, 5.0-24.1\%), and $4.5 \%$ (95\% CI, $0.8-8.4 \%$ ) in the odds of pediatric pneumonia ED visits, respectively. Meanwhile, the IQR increase in $\mathrm{O}_{3}$ level was associated with a $6.6 \%(95 \% \mathrm{CI}$, $-0.2-13.9 \%)$, not significantly related to pediatric pneumonia ED visits.

A two-pollutant model was used to determine which individual contaminant influences the number of pediatric pneumonia ED visits independently of other pollutant effects. In accordance with the results obtained from the single-pollutant models, the multi-pollutant models were fitted with different pollutant combinations (with up to two pollutants per model) to assess the stability of the effects of PM. The results obtained are presented in Table 4. An IQR increase in $\mathrm{PM}_{2.5}$ was significantly related to ED visits for pediatric pneumonia after adjustment for $\mathrm{PM}_{10}(\mathrm{OR}=1.179,95 \% \mathrm{CI}: 1.009$ $1.378 \%)$ and $\mathrm{SO}_{2}(\mathrm{OR}=1.119,95 \% \mathrm{CI}: 1.027-1.219 \%)$. An IQR increase in $\mathrm{NO}_{2}$ was significantly associated with ED visits for pediatric pneumonia after adjustment

Table 2 Summarized statistics for meteorology and air pollution in Kaohsiung, 2008-2014

\begin{tabular}{llllllll}
\hline Percentiles & \multicolumn{1}{l}{ Minimum } & $25 \%$ & $50 \%$ & $75 \%$ & Maximum & Mean & IQR \\
\hline & 3.6 & 23.2 & 40.5 & 54.6 & 126.7 & 41.1 & 31.4 \\
\hline $\mathrm{PM}_{2.5}\left(\mu \mathrm{g} / \mathrm{m}^{3}\right)$ & 3.6 & 43.1 & 70.7 & 95.7 & 582.0 & 72.8 & 52.6 \\
$\mathrm{PM}_{10}\left(\mu \mathrm{g} / \mathrm{m}^{3}\right)$ & 14.7 & 13.2 & 18.4 & 24.3 & 24.3 & 19.1 & 11.1 \\
$\mathrm{NO}_{2}(\mathrm{ppb})$ & 3.9 & 4.9 & 6.1 & 7.8 & 17.2 & 6.4 & 2.9 \\
$\mathrm{SO}_{2}(\mathrm{ppb})$ & 1.8 & 19.0 & 28.1 & 37.5 & 74.6 & 29.1 & 18.5 \\
$\mathrm{O}_{3}(\mathrm{ppb})$ & 3.5 & 22.3 & 26.4 & 28.8 & 32.1 & 25.3 & 6.5 \\
Temperature $\left({ }^{\circ} \mathrm{C}\right)$ & 12.4 & 70.0 & 74.0 & 78.1 & 95.3 & 74.0 & 8.1 \\
\hline Humidity (\%) & 44.0 & &
\end{tabular}

The missing data for all monitor stations were less than $1 \%$ 
Table 3 Spearman correlation coefficients between air pollutants and weather conditions during the 7-year study period (upper right triangle), and during the warm period (lower left triangle)

\begin{tabular}{llllllll}
\hline & $\mathrm{PM}_{2.5}$ & $\mathrm{PM}_{10}$ & $\mathrm{NO}_{2}$ & $\mathrm{SO}_{2}$ & $\mathrm{O}_{3}$ & Temperature & Humidity \\
\hline $\mathrm{PM}_{2.5}$ & 1.000 & 0.915 & 0.802 & 0.516 & 0.427 & -0.570 & -0.406 \\
$\mathrm{PM}_{10}$ & 0.915 & 1.000 & 0.758 & 0.472 & 0.422 & -0.544 & -0.441 \\
$\mathrm{NO}_{2}$ & 0.694 & 0.705 & 1.000 & 0.509 & 0.116 & -0.758 & -0.323 \\
$\mathrm{SO}_{2}$ & 0.396 & 0.392 & 0.481 & 1.000 & 0.209 & -0.206 & -0.302 \\
$\mathrm{O}_{3}$ & 0.775 & 0.750 & 0.489 & 0.226 & 1.000 & 0.068 & -0.397 \\
Temperature & -0.355 & -0.393 & -0.589 & -0.163 & -0.296 & 1.000 & 0.257 \\
Humidity & -0.233 & -0.266 & -0.054 & -0.120 & -0.303 & -0.258 & 1.000 \\
\hline
\end{tabular}

for $\mathrm{PM}_{10}(\mathrm{OR}=1.106,95 \% \mathrm{CI}: 1.004-1.218 \%)$ and $\mathrm{SO}_{2}$ $(\mathrm{OR}=1.115$, 95\% CI: 1.015-1.226\%). Associations with pneumonia ED visits were no longer significant when $\mathrm{PM}_{2.5}$ was adjusted for $\mathrm{NO}_{2} \quad(\mathrm{OR}=1.089$, 95\% CI: $0.986-1.202 \%)$ or when $\mathrm{NO}_{2}$ was adjusted for $\mathrm{PM}_{2.5}$ (OR $=1.088$, 95\% CI: 0.984-1.203\%) in two-pollutant models.

Figure 2 presents the results of the stratified analysis to examine the effect of $\mathrm{PM}_{2.5}$ and $\mathrm{NO}_{2}$ on pediatric pneumonia according to different seasons, temperature, and underlying diseases on lag 3, after adjustment for temperature and humidity. As shown in Fig. 2a, older children (aged $\geq 4$ years) were more susceptible to $\mathrm{PM}_{2.5}$; an increase in the IQR for $\mathrm{PM}_{2.5}$ was associated with increases in the odds of ED visits for pneumonia of $21.7 \%$ (95\% CI, 9.9-34.8\%) for older children and 1.7\% (95\% CI, - 11.3- 16.7\%; interaction $p=0.024$ ) for younger children (aged $<4$ years). The children were more susceptible to $\mathrm{NO}_{2}$ during the warm days $\left(\geq 26.5^{\circ} \mathrm{C}\right)$ than during the cool days $\left(<26.5^{\circ} \mathrm{C}\right)$ (Fig. $\left.2 \mathrm{~b}\right)$, an increase in the IQR for $\mathrm{NO}_{2}$ was associated with increases of $35.4 \%$ (95\% CI, 13.6-61.3\% and 8.5\% (95\% CI, - 2.7- 20.9\%; interaction $p=0.011$ ) in the odds of ED visits for pneumonia, respectively. There were no significant differences with respect to the effects of $\mathrm{PM}_{2.5}$ or $\mathrm{NO}_{2}$ on

Air pollutants, unit

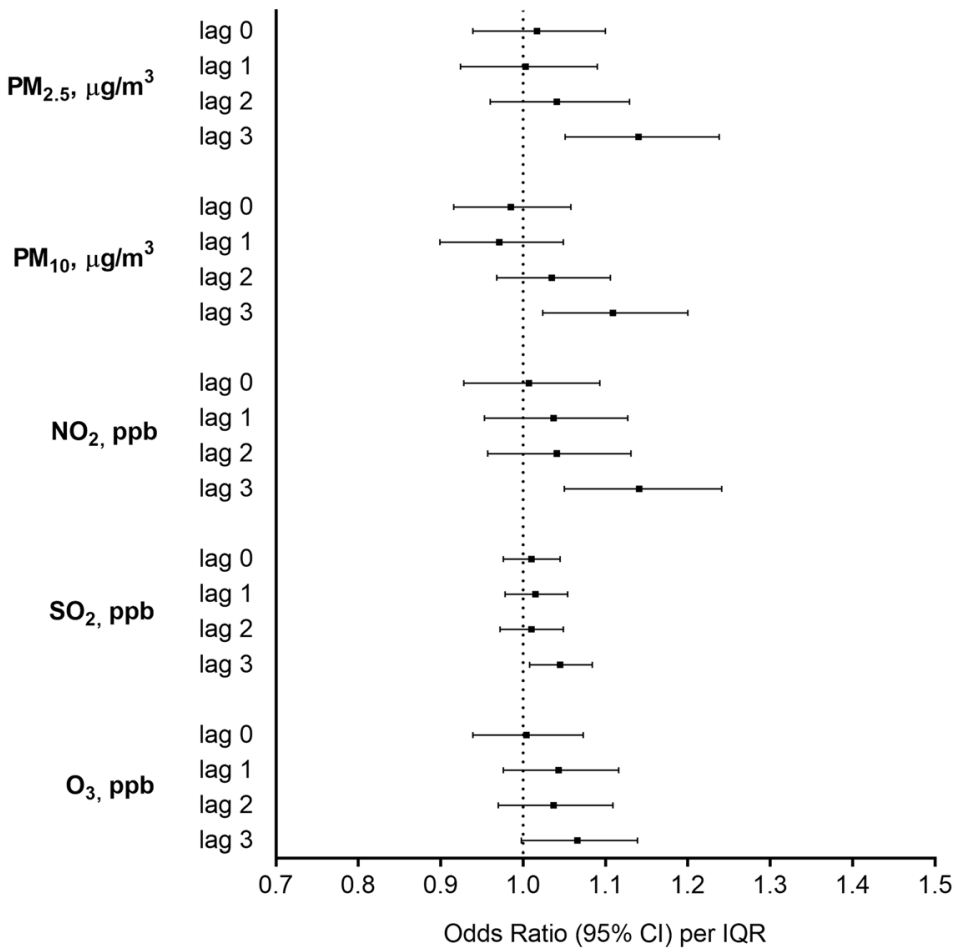

Fig. 1 Odds ratios (ORs) and 95\% confidence intervals (Cls) for pediatric pneumonia ED visits associated with IQR increments in air pollutant levels, with adjustment for temperature and humidity. ED, emergency department; IQR, interquartile range 
Table 4 Emergency department visits for each interquartile range change in the two-pollutant models

OR $(95 \% \mathrm{Cl})$ of pneumonia

Adjusted for temperature, humidity, and pollutant

\begin{tabular}{llllll}
\hline \multicolumn{2}{l}{ Single-pollutant model } & Adjusted $\mathrm{PM}_{2.5}$ & Adjusted $\mathrm{PM}_{2.5-10}$ & Adjusted $\mathrm{NO}_{2}$ & Adjusted $\mathrm{SO}_{2}$ \\
\hline $\mathrm{PM}_{2.5}$ & $1.140(1.051-1.238)$ & & $1.156(1.055-1.267)$ & $1.089(0.986-1.202)$ & $1.119(1.027-1.219)$ \\
$\mathrm{NO}_{2}$ & $1.141(1.050-1.241)$ & $1.088(0.984-1.203)$ & $1.136(1.040-1.240)$ & & $1.115(1.015-1.226)$ \\
$\mathrm{SO}_{2}$ & $1.045(1.008-1.084)$ & $1.030(0.991-1.070)$ & $1.042(1.004-1.082)$ & $1.022(0.981-1.066)$ & \\
\hline
\end{tabular}

$\mathrm{PM}_{2.5-10}$ : Particulate matter with an aerodynamic diameter between 2.5 and $10 \mu \mathrm{m}$.

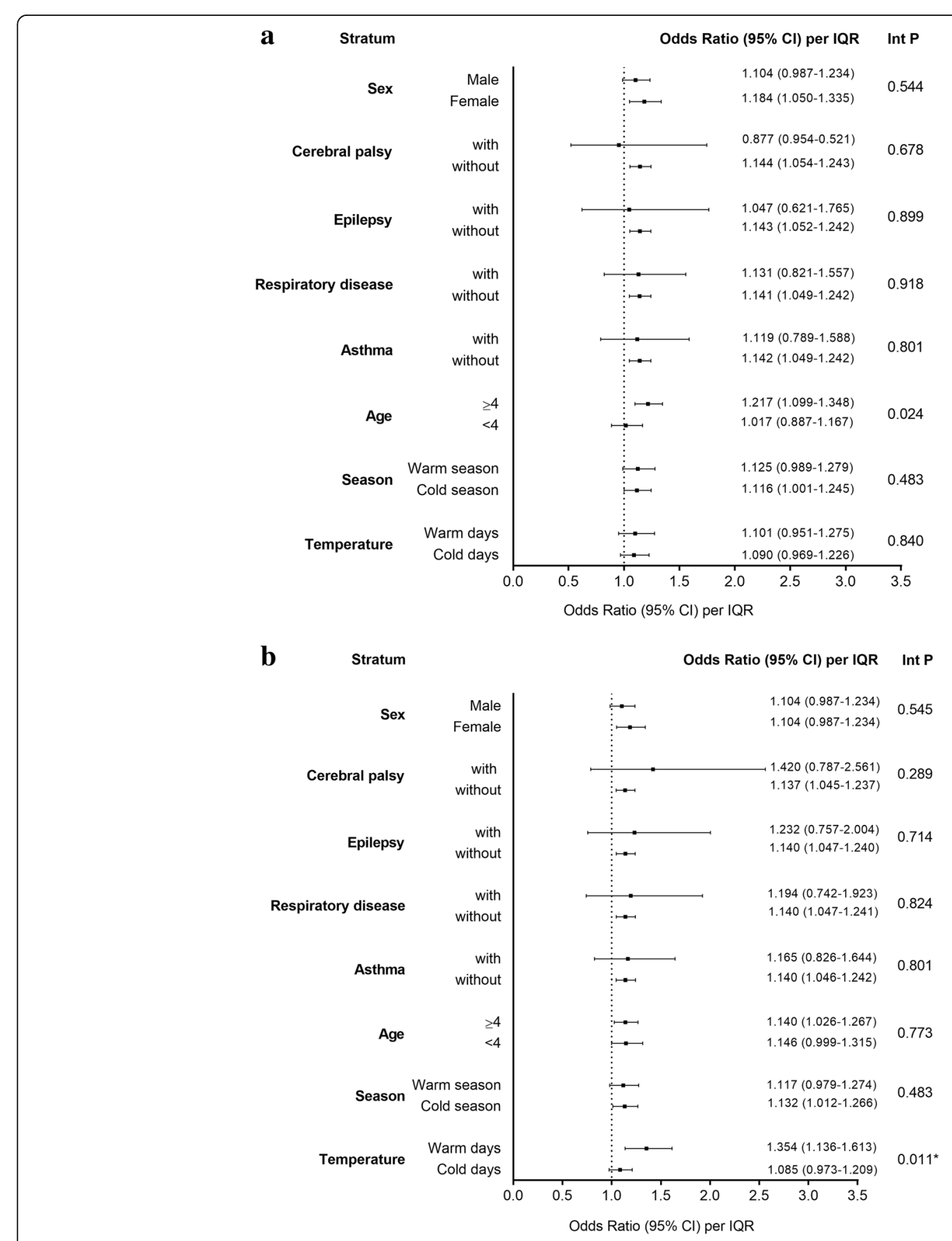

Fig. 2 Odds ratios (ORs) for IQR increments in (a) $\mathrm{PM}_{2.5}$ and (b) $\mathrm{NO}_{2}$ on lag 3 after adjustment for temperature and humidity. The $x$-axis represents $\mathrm{OR}$ with $95 \%$ confidence intervals (Cls). The warm season was from April to September. ${ }^{*} p<0.05$. Int $\mathrm{P}$, interaction $p$-value; IQR, interquartile range 
pediatric pneumonia between the male and female patients, between those with or without underlying cerebral palsy, epilepsy, respiratory disease, or asthma, and between different seasons or temperatures.

\section{Discussion}

In this study, we estimated the effects of PM and other air pollutants on pediatric pneumonia and found that $\mathrm{PM}_{2.5}$ and $\mathrm{NO}_{2}$ possibly play important roles in pediatric pneumonia events in Kaohsiung, Taiwan. Of all pollutant exposures included in the analysis, the odds of pediatric pneumonia following $\mathrm{PM}_{2.5}$ exposure was greater in older children. Additionally, the effect of $\mathrm{NO}_{2}$ on pediatric pneumonia was more significant during warm days.

Recently, many studies have focused on the association between $\mathrm{PM}_{2.5}$ and human health, especially in respiratory and cardiovascular diseases. Several previous studies demonstrated a positive association between $\mathrm{PM}_{2.5}$ and pediatric respiratory disease, such as upper respiratory infection and asthma [23, 24]. Some epidemiological studies have also demonstrated positive associations between $\mathrm{PM}_{2.5}$ and pediatric pneumonia. Lv et al. demonstrated increased risk of hospital admissions for pediatric pneumonia for $\mathrm{PM}_{2.5}$ on lag 4 [18]. Xiao et al. reported that air pollutants, including $\mathrm{PM}_{2.5}$, were associated with pediatric ED visits for respiratory tract infections on lag 0-3 [25]. On the other hand, some studies did not show statistically significant associations of the short-term effect of $\mathrm{PM}_{2.5}$ concentrations on pediatric pneumonia $[24,26,27]$. The difference between these studies should be considered with caution for several reasons. First, Strickland et al. examined lag 0-1 [24], and Malig et al. examined lag 0-2 [27], which revealed no statistically significant association between $\mathrm{PM}_{2.5}$ and pneumonia. Our study demonstrated a positive correlation between $\mathrm{PM}_{2.5}$ and pediatric pneumonia ED visits on lag 3; Lv et al.'s study on lag 4 and Xiao et al.'s study on lag $0-3$ had the same result $[18,25]$. Strickland et al.'s and Malig et al.'s studies did not examine the day before admission eariler than lag 1 and lag 2 [24, 27], respectively, and this difference may have contributed to the different results. Second, the different chemical components of $\mathrm{PM}_{2.5}$ may have different health effects. Darrow et al. observed that the carbon fraction of $\mathrm{PM}_{2.5}$, particularly organic carbon, was positively associated with pediatric pneumonia, but the total $\mathrm{PM}_{2.5}$ showed a negative association [26]. Xiao et al. estimated joint effects from $\mathrm{O}_{3}$ and $\mathrm{PM}_{2.5}$ components $\mathrm{SO}_{4}{ }^{2-}, \mathrm{NO}_{3}{ }^{-}$, and $\mathrm{NH}_{4}{ }^{+}$, and found the result was significantly associated with increased odds of pediatric pneumonia [25]. The different PM components of different regions may have contributed to different results.

$\mathrm{PM}_{2.5}$ has been reported to contribute to varying human health effects in different age groups. A case-crossover study found people of advanced age were more susceptible to the adverse effects of $\mathrm{PM}_{2.5}$ on OHCA [15]. Few studies have performed age group analyses of the effects of PM on pediatric pneumonia. Darrow et al. reported that hazard ratios tended to be higher in children aged 1-4 years compared with infants less than 1 year of age on pediatric pneumonia, but the interaction $p$ values were not calculated in the study [26]. Lv et al. implied that young children $(<1$ year) were at the highest risk of hospital admission for pneumonia due to airborne PM, but the interaction $\mathrm{p}$ values were also not evaluated [18]. The present study demonstrated that the odds of pediatric pneumonia following $\mathrm{PM}_{2.5}$ exposure was greater in older children $(\geq 4$ years old, interaction $p=0.024$ ). One possible reason for this result was that children of different ages might spend different amounts of time outdoors, leading to varying air pollution exposure. Furthermore, air pollutants seem to have varying health effects on different age groups. Hassanvand et al. found that PM was not associated with increased highsensitivity C-reactive protein (hsCRP) in healthy young adults, whereas in elderly subjects, hsCRP increased with $\mathrm{PM}_{2.5}$ exposure [8]. Using urinary malondialdehyde as a biomarker of oxidative stress, Kim et al. concluded that elderly adults are more susceptible than young children to ambient fine particulates and related oxidative stress [28].

Several studies tried to identify the mechanism by which PM contributes to pneumonia. An animal study found that $\mathrm{PM}_{2.5}$ exposure was associated with increased levels of DNA lesions in mouse lungs [29]. Through microfluidic chips, Schulze et al. concluded that $\mathrm{PM}_{2.5}$ interferes with alveolar macrophages, and pulmonary epithelial cells stimulate the release of a variety of cytokines and lead to inflammation [30]. Hassanvand et al. provided evidence that short-term exposure to $\mathrm{PM}_{2.5}$ was linked to elevated inflammation and coagulation of blood markers [8]. Zhang et al. reported that short-term $\mathrm{PM}_{2.5}$ exposure was associated with airway inflammation in school children [31]. A review article demonstrated that $\mathrm{PM}_{2.5}$ and $\mathrm{PM}_{10}$ exposure was associated with increased instances of pediatric pneumonia [19]. The present study also supported these results, and we found a positive association between $\mathrm{PM}_{2.5}$ and pediatric pneumonia ED visits.

$\mathrm{NO}_{2}$ has been found to be associated with all-cause mortality [32], cardiovascular mortality [33], hospital admissions for cardiovascular disease [34], and admission for pneumonia [35]. Toxicological studies have suggested that $\mathrm{NO}_{2}$ might damage macrophages, natural killer cells, and $\mathrm{CD} 4$ to $\mathrm{CD} 8$ ratios in the respiratory tract, leading to decreased mucociliary clearance and vulnerable respiratory epithelium [36]. However, the association between $\mathrm{NO}_{2}$ and pediatric pneumonia remains controversial. Some studies demonstrated the acute effect of $\mathrm{NO}_{2}$ exposure leading to ED visits for pediatric pneumonia [26, 37]. On 
the other hand, another study did not find a positive effect between $\mathrm{NO}_{2}$ and pediatric pneumonia [25]. A systematic review including 17 studies concluded that $\mathrm{NO}_{2}$ was associated with an increase in hospital admissions due to pediatric pneumonia [19]. The current study had a similar result, and we found that $\mathrm{NO}_{2}$ might play an important role in pediatric pneumonia ED visits.

Seasonal variation seems to play an important role on air pollutants and human health. Szyszkowiczet al. demonstrated that the associations between air pollutants and respiratory health outcomes were stronger during the warm season [38]. Dong et al. implied the effects of $\mathrm{NO}_{2}$ and $\mathrm{SO}_{2}$ on daily ischemic stroke counts were stronger in the cold season than in the warm season [39]. Cheng et al. found a stronger association between $\mathrm{PM}_{2.5}$ and pneumonia with septicemia ED visits during the warm season [4]. Ueda et al. found that $\mathrm{PM}_{2.5}$ mass correlated with increased all-cause mortality, especially in transitional seasons rather than in summer and winter [40]. Few studies have focused on the seasonal effects of air pollution on pediatric pneumonia. Lv et al. revealed that children were at higher risk of hospital admission for pneumonia due to airborne PM, particularly on warm days [18]; but seasonal differences were not observed in another study [26]. In addition, although the risk was higher on warm days in $\mathrm{Lv}$ et al.'s study [18], the interaction $p$-value was not calculated in that study. The present study revealed that ORs for $\mathrm{NO}_{2}$ were higher during the warm days $(p=0.011)$. One possible reason for this result is that variable concentrations of air pollutants and each PM component may relate to seasonal differences in human health [40, 41]. Seasonal variations may also result from different patterns of exposure to air pollutants. People tend to stay inside when weather conditions are extremely hot or cold, and thus decrease their exposure to outdoor air pollutants. When staying indoors, a positive correlation between the numbers of open windows for ventilation and exposure to air pollutants was observed [42]. In addition, meteorological factors might affect the health effect of air pollutants. Huang et al. demonstrated that the combination of low temperatures and high PM was associated with a greater incidence of developing acute coronary syndrome [43]. The combination of weather variation and lifestyle change might lead to the different health effects of air pollutants.

There are certain limitations to our study. First, the study was conducted in an industrial city having a tropical monsoon climate; the mixture of air pollutants and seasonal effects may be different in other regions. Second, as an exposure estimate for the entire population, we analyzed air pollution data from fixed monitoring sites assuming the exposure to be homogenous across the whole area. Factors such as personal protective equipment use and time spent outdoors may affect personal exposure. Third, individuals were identified in a single tertiary medical center, which limited the sample size. Moreover, individual susceptibility might vary due to ethnic differences. Thus, further studies should be conducted in more regions with larger samples and include seasonal constituent analysis.

\section{Conclusions}

We found that $\mathrm{PM}_{2.5}$ and $\mathrm{NO}_{2}$ possibly play important roles in pediatric pneumonia events in Kaohsiung. Older children were found to be more susceptible to the adverse effects of $\mathrm{PM}_{2.5}$. Additionally, the health effects of the different air pollutants varied with temperature and patients were more susceptible to $\mathrm{NO}_{2}$ during the warm days.

\section{Abbreviations \\ $\mathrm{Cl}$ : Confidence interval; ED: Emergency department; IQR: Interquartile range; $\mathrm{NO}_{2}$ : Nitrogen dioxide; $\mathrm{O}_{3}$ : Ozone; OHCA: Out-of-hospital cardiac arrest; OR: Odds ratios; PM: Particulate matter; $\mathrm{PM}_{10}$ : Particulate matter with diameter $<10 \mu \mathrm{m} ; \mathrm{PM}_{2.5}$ : Particulate matter with diameter $<2.5 \mu \mathrm{m}$; SD: Standard deviation; $\mathrm{SO}_{2}$ : Sulfur dioxide}

\section{Acknowledgements}

We appreciate the support provided for statistics at the Biostatistics Center of Kaohsiung Chang Gung Memorial Hospital.

\section{Authors' contributions}

CYC and SYC conceived the manuscript, performed the analyses, and wrote the manuscript. CCC and HYP contributed to data collection and measurements. KHW was involved mainly in data analysis and quality management. FJC provided overall supervision, edited the manuscript, and undertook the responsibility of submitting the manuscript for publication. CYC and SYC contributed equally and are considered co-first authors. All authors read and approved the final manuscript.

\section{Funding}

This study was supported in part by research grants from the Kaohsiung Chang Gung Memorial Hospital [CMRP-G8H1081].

\section{Availability of data and materials}

The datasets used and analyzed during the current study are available from the corresponding author on reasonable request.

Ethics approval and consent to participate

Not applicable.

Consent for publication

Not applicable.

\section{Competing interests}

The authors declare that they have no competing interests.

\section{Author details}

${ }^{1}$ Department of Emergency Medicine, Kaohsiung Chang Gung Memorial Hospital, No. 123, Dapi Rd., Niaosong Township, Kaohsiung, County 833, Taiwan. ${ }^{2}$ Chang Gung University College of Medicine, No.259, Wenhua 1st Road, Guishan District, Taoyuan City 333, Taiwan. ${ }^{3}$ Department of Emergency Medicine, Yunlin Chang Gung Memorial Hospital, No. 1500, Gongye Rd, Mailiao Township, Yunlin County 638, Taiwan.

Received: 25 May 2019 Accepted: 22 August 2019

Published online: 28 August 2019

\section{References}

1. Kim TY, Kim H, Yi SM, Cheong JP, Heo J. Short-term effects of ambient PM2. 5 and PM2.5-10 on mortality in major cities of Korea. Aerosol Air Qual Res. 2018;18:1853-62. https://doi.org/10.4209/aaqr.2017.11.0490. 
2. Cheng MH, Chiu HF, Yang CY. Coarse particulate air pollution associated with increased risk of hospital admissions for respiratory diseases in a tropical city, Kaohsiung, Taiwan. Int J Environ Res Public Health. 2015;12: 13053-68. https://doi.org/10.3390/ijerph121013053.

3. Weichenthal S, Kulka R, Lavigne E, Van Rijswijk D, Brauer M, Villeneuve PJ, Stieb D, Joseph L, Burnett RT. Biomass burning as a source of ambient fine particulate air pollution and acute myocardial infarction. Epidemiology. 2017;28:329-37. https://doi.org/10.1097/EDE.0000000000000636.

4. Cheng FJ, Lee KH, Lee CW, Hsu PC. Association between particulate matter air pollution and hospital emergency room visits for pneumonia with septicemia: a retrospective analysis. Aerosol Air Qual Res. 2019;19:345-54. https://doi.org/10.4209/aagr.2018.08.0285.

5. Cheng MF, Tsai SS, Chiu HF, Sung FC, Wu TN, Yang CY. Air pollution and hospital admissions for pneumonia: are there potentially sensitive groups? Inhal Toxicol. 2009;21:1092-8. https://doi.org/10.3109/08958370902744855.

6. Ren M, Fang X, Li M, Sun S, Pei L, Xu Q, Ye X, Cao Y. Concentrationresponse relationship between PM2.5 and daily respiratory deaths in China: A systematic review and metaregression analysis of time-series studies. Biomed Res Int. 2017;2017:5806185. https://doi.org/10.1155/2017/5806185.

7. Walker CLF, Rudan I, Liu L, Nair H, Theodoratou E, Bhutta ZA, O'Brien KL, Campbell H, Black RE. Global burden of childhood pneumonia and diarrhoea. Lancet. 2013;381:1405-16. https://doi.org/10.1016/S0140-6736(13)60222-6.

8. Hassanvand MS, Naddafi K, Kashani H, Faridi S, Kunzli N, Nabizadeh R, Momeniha F, Gholampour A, Arhami M, Zare A, Pourpak Z. Short-term effects of particle size fractions on circulating biomarkers of inflammation in a panel of elderly subjects and healthy young adults. Environ Pollut. 2017; 223:695-704. https://doi.org/10.1016/.envpol.2017.02.005.

9. Ji X, Han $M$, Yun $Y$, Li G, Sang N. Acute nitrogen dioxide $\left(\mathrm{NO}_{2}\right)$ exposure enhances airway inflammation via modulating Th1/Th2 differentiation and activating JAK-STAT pathway. Chemosphere. 2015;120:722-8. https://doi. org/10.1016/j.chemosphere.

10. Xing YF, Xu YH, Shi MH, Lian YX. The impact of PM2.5 on the human respiratory system. J Thorac Dis. 2016;8:E69-74. https://doi.org/10.3978/j. issn.2072-1439.2016.01.19.

11. Bell ML, Ebisu K, Peng RD, Walker J, Samet JM, Zeger SL, Dominici F. Seasonal and regional short-term effects of fine particles on hospital admissions in 202 US counties, 1999-2005. Am J Epidemiol. 2008;168:130110. https://doi.org/10.1093/aje/kwn252.

12. Bell ML, Ebisu K, Peng RD, Dominici F. Adverse health effects of particulate air pollution:modification by air conditioning. Epidemiology. 2009;20:682-6. https://doi.org/10.1097/EDE.0b013e3181aba749.

13. Zeka A, Zanobetti A, Schwartz J. Short term effects of particulate matter on cause specific mortality: effects of lags and modification by city characteristics. Occup Environ Med. 2005;62:718-25. https://doi.org/10.1136/ oem.2004.017012.

14. Qiu H, Tian LW, Pun VC, Ho KF, Wong TW, Ignatius TS. Coarse particulate matter associated with increased risk of emergency hospital admissions for pneumonia in Hong Kong. Thorax. 2014;69:1027-33. https://doi.org/10.1136/ thoraxjnl-2014-205429.

15. Xia R, Zhou G, Zhu T, Li X, Wang G. Ambient air pollution and out-ofhospital cardiac arrest in Beijing. China Int J Environ Res Public Health. 2017; 14:423. https://doi.org/10.3390/ijerph14040423.

16. Bono R, Romanazzi V, Bellisario V, Tassinari R, Trucco G, Urbino A, Cassardo C, Siniscalco C, Marchetti P, Marcon A. Air pollution, aeroallergens and admissions to pediatric emergency room for respiratory reasons in Turin, northwestern Italy. BMC Public Health. 2016;16:722. https://doi.org/10.1186/ s12889-016-3376-3.

17. Lim H, Kwon HJ, Lim JA, Choi JH, Ha M, Hwang SS, Choi WJ. Short-term effect of fine particulate matter on children's hospital admissions and emergency department visits for asthma: a systematic review and metaanalysis. J Prev Med Public Health. 2016:49:205-19. https://doi.org/10.3961/ jpmph.16.037.

18. Lv C, Wang X, Pang N, Wang L, Wang Y, Xu T, Zhang Y, Zhou T, Li W. The impact of airborne particulate matter on pediatric hospital admissions for pneumonia among children in Jinan, China: a case-crossover study. J Air Waste Manage Assoc. 2017;67:669-76. https://doi.org/10.1080/10962247.2016.1265026.

19. Nhung NTT, Amini H, Schindler C, Joss MK, Dien TM, Probst-Hensch N, Perez L, Künzli N. Short-term association between ambient air pollution and pneumonia in children: a systematic review and meta-analysis of time-series and case-crossover studies. Environ Pollut. 2017;230:1000-8. https://doi. org/10.1016/j.envpol.2017.07.063.
20. Maclure M. The case-crossover design: a method for studying transient effects on the risk of acute events. Am J Epidemiol. 1991;133:144-53. https://doi.org/10.1093/oxfordjournals.aje.a115853.

21. Janes $\mathrm{H}$, Sheppard L, Lumley T. Case-crossover analyses of air pollution exposure data: referent selection strategies and their implications for bias. Epidemiology. 2005;16:717-26. https://doi.org/10.1097/01.ede.0000181315.1 8836.9d.

22. Peng RD, Dominici F, Pastor-Barriuso R, Zeger SL, Samet JM. Seasonal analyses of air pollution and mortality in 100 US cities. Am J Epidemiol. 2005;161:585-94. https://doi.org/10.1093/aje/kwi075.

23. Gleason JA, Bielory L, Fagliano JA. Associations between ozone, PM2.5, and four pollen types on emergency department pediatric asthma events during the warm season in New Jersey: a case-crossover study. Environ Res. 2014;132:421-9. https://doi.org/10.1016/j.envres.2014.03.035.

24. Strickland MJ, Hao H, Hu X, Chang HH, Darrow LA, Liu Y. Pediatric emergency visits and short-term changes in PM2.5 concentrations in the $\mathrm{U}$. S. state of Georgia. Environ Health Perspect. 2016;124:690-6. https://doi. org/10.1289/ehp.1509856.

25. Xiao Q, Liu Y, Mulholland JA, Russell AG, Darrow LA, Tolbert PE, Strickland MJ. Pediatric emergency department visits and ambient Air pollution in the U.S. State of Georgia: a case-crossover study. Environ Health. 2016;15:115. https://doi.org/10.1186/s12940-016-0196-y.

26. Darrow LA, Klein M, Flanders WD, Mulholland JA, Tolbert PE, Strickland MJ. Air pollution and acute respiratory infections among children 0-4 years of age: an 18-year time-series study. Am J Epidemiol. 2014;180:968-77. https:// doi.org/10.1093/aje/kwu234

27. Malig BJ, Green S, Basu R, Broadwin R. Coarse particles and respiratory emergency department visits in California. Am J Epidemiol. 2013;178:58-69. https://doi.org/10.1093/aje/kws451

28. Kim K, Park EY, Lee KH, Park JD, Kim YD, Hong YC. Differential oxidative stress response in young children and the elderly following exposure to PM (2.5). Environ Health Prev Med. 2008;14:60-6. https://doi.org/10.1007/s12199-008-0060-y.

29. de Oliveira AAF, de Oliveira TF, Dias MF, Medeiros MHG, Di Mascio P, Veras M, Lemos M, Marcourakis T, Saldiva PHN, Loureiro APM. Genotoxic and epigenotoxic effects in mice exposed to concentrated ambient fine particulate matter (PM (2.5)) from São Paulo city, Brazil. Part Fibre Toxicol. 2018;15:40. https://doi.org/10.1186/s12989-018-0276-y.

30. Schulze F, Gao X, Virzonis D, Damiati S, Schneider M, Kodzius R. Air quality effects on human health and approaches for its assessment through microfluidic chips. Genes. 2017;8:244. https://doi.org/10.3390/genes8100244.

31. Zhang Y, Salam MT, Berhane K, Eckel SP, Rappaport EB, Linn WS, Habre R, Bastain TM, Gilliland FD. Genetic and epigenetic susceptibility of airway inflammation to PM2.5 in school children: new insights from quantile regression. Environ Health. 2017;16:88. https://doi.org/10.1186/s12940-017-0285-6.

32. Eum KD, Kazemiparkouhi F, Wang B, Manjourides J, Pun V, Pavlu V, Suh H. Long-term $\mathrm{NO}_{2}$ exposures and cause-specific mortality in American older adults. Environ Int. 2019;124:10-5. https:/doi.org/10.1016/j.envint.2018.12.060.

33. Liu Y, Chen X, Huang S, Tian L, Lu YA, Mei Y, Ren M, Li N, Liu L, Xiang H. Association between air pollutants and cardiovascular disease mortality in Wuhan, China. Int J Environ Res Public Health. 2015;12:3506-16. https://doi. org/10.3390/ijerph120403506.

34. Collart P, Dubourg D, Levêque A, Sierra NB, Coppieters Y. Short-term effects of nitrogen dioxide on hospital admissions for cardiovascular disease in Wallonia. Belgium Int J Cardiol. 2018;255:231-6. https://doi.org/10.1016/j. ijcard.2017.12.058

35. Cheng MF, Tsai SS, Wu TN, Chen PS, Yang CY. Air pollution and hospital admissions for pneumonia in a tropical city: Kaohsiung. Taiwan J Toxicol Environ Health A. 2007;70:2021-6. https://doi.org/10.1080/15287390701601020.

36. Frampton MW, Boscia J, Roberts NJ Jr. Nitrogen dioxide exposure: effects on airway and blood cells. Am J Phys Lung Cell Mol Phys. 2002;282:L155-65. https://doi.org/10.1152/ajplung.2002.282.1.L155.

37. Negrisoli J, Nascimento LFC. Atmospheric pollutants and hospital admissions due to pneumonia in children. Rev Paul Pediatr. 2013;31:501-6. https://doi.org/10.1590/1516-3180.2014.00122601.

38. Szyszkowicz M, Kousha T, Castner J, Dales R. Air pollution and emergency department visits for respiratory diseases: a multi-city case crossover study. Environ Res. 2018;163:263-9. https://doi.org/10.1016/j.envres.2018.01.043.

39. Dong H, Yu Y, Yao S, Lu Y, Chen Z, Li G, Yao Y, Yao X, Wang SL, Zhang Z. Acute effects of air pollution on ischaemic stroke onset and deaths: a timeseries study in Changzhou. China BMJ Open. 2018;8:e020425. https://doi. org/10.1136/bmjopen-2017-020425. 
40. Ueda K, Yamagami M, Ikemori F, Hisatsune K, Nitta H. Associations between fine particulate matter components and daily mortality in Nagoya. Japan J Epidemiol. 2016;26:249-57. https://doi.org/10.2188/jea.JE20150039.

41. Zeb B, Alam K, Sorooshian A, Blaschke T, Ahmad I, Shahid I. On the morphology and composition of particulate matter in an urban environment. Aerosol Air Qual Res. 2018;18:1431-47. https://doi.org/10.4209/ aaqr.2017.09.0340.

42. Sarnat JA, Koutrakis P, Suh HH. Assessing the relationship between personal particulate and gaseous exposures of senior citizens living in Baltimore. MD J Air Waste Manag Assoc. 2000;50:1 184-98. https://doi.org/10.1080/104732 89.2000.10464165.

43. Huang $C H$, Lin $H C$, Tsai CD, Huang HK, Lian IB, Chang CC. The interaction effects of meteorological factors and air pollution on the development of acute coronary syndrome. Sci Rep. 2017;7:44004. https://doi.org/10.1038/ srep44004.

\section{Publisher's Note}

Springer Nature remains neutral with regard to jurisdictional claims in published maps and institutional affiliations.

Ready to submit your research? Choose BMC and benefit from:

- fast, convenient online submission

- thorough peer review by experienced researchers in your field

- rapid publication on acceptance

- support for research data, including large and complex data types

- gold Open Access which fosters wider collaboration and increased citations

- maximum visibility for your research: over $100 \mathrm{M}$ website views per year

At BMC, research is always in progress.

Learn more biomedcentral.com/submissions 